\title{
Identifying Objectives for Breeding Improved Vegetable Varieties-Hard but Vital Choice
}

\author{
Prem Nath ${ }^{*}$ \\ Chairman, Dr. P.N. Agricultural Science Foundation (PNASF), Bangalore, India \\ *Corresponding author: drpremnath@vsnl.net
}

Received July 23, 2014; Revised October 18, 2014; Accepted November 04, 2014

\begin{abstract}
The vegetable breeding experience confirms that identifying objectives of breeding is prelude and key to successful results of a breeding programme in developing improved verities. In order to identify the objectives, the views of the choice makers must be considered which will ensure the acceptance and popularity among the farmers and consumers. Practical examples have been illustrated.
\end{abstract}

Keywords: choice, choice makers, introduction, objectives of breeding, vegetable breeding

Cite This Article: Prem Nath, "Identifying Objectives for Breeding Improved Vegetable Varieties-Hard but Vital Choice.” Journal of Food and Nutrition Research, vol. 2, no. 12 (2014): 867-871. doi: 10.12691/jfnr-2-12-1.

\section{Introduction}

For long I was wondering why several of the new vegetable varieties developed by the public research institutions and universities did not become popular among the growers and why many of the varieties developed by national and multinational private companies became so commercialized in India and in some other countries. Contrary to this, most of the vegetable varieties developed either by public or private sector were much acceptable to both growers and consumers in western countries.

To me it looks like, once the crop is identified for improvement by breeding the author and his/her research team must thoroughly investigate various objectives of breeding and be fully convinced of the objectives before launching the breeding project. The main focus and goal will be to develop a variety suitable not only for growers but for both growers and consumers. Hence, the choice of objectives becomes hard but vital. The failure of a new improved variety in terms of time and economic loss has been colossal, which seems to have gone unnoticed by research communities.

\section{Search of Objectives}

During my research career as a vegetable breeder, I considered myself as an architect. The breeder constructs a beautiful and useful plant, whereas the architect constructs a beautiful and purposeful building. It takes few too many years to develop a plant variety whereas an architect takes few years only to construct a building but the fruitful life of the former is shorter than the later. At the end, the critical and vital role of breeder/architect has no chance to neglect the choice or choices of beneficiary or client. A breeding cannot be launched unless the objectives are defined clearly which varies from crop to crop, season to season, location to location, client to client. This is the beginning of research by the breeder concerned-the task of narrowing down the choices of objectives which matter most. Like building blueprint, a plant blueprint needs to be prepared including height and morphological structure, fruit bearing capacity, resistance tolerance to something, taste of consumers, suitability in cropping pattern, lastly most important one, the location. Any of these lapses may result in the failure of the outcome.

\section{Choices of Objectives}

With my experience, it is important to know from where the choice is originating from, it could be national/state priority to grow this crop, or could be programme/project to augment vitamin availability among masses, or could be most popular color and shape among consumers, or could be most profitable for the growers, or could have good transport quality for marketing, or could be a need of severe disease resistance variety for the growers and so on. It boils down to confirm that directly or remotely decision makers of choices are policy makers, growers, traders, consumers and lastly the researchers. This is hard because the grain breeders do not require dealing with many of these choice makers. It makes easier for the vegetable breeders to reach directly to the choice makers, listen and list their choices and narrows it down to define the objectives of the breeding programme.

\section{Choice Makers}

\subsection{Nation or State}

Either national or state government agricultural policies have an already listed priority of crops, which include both major and minor crops. Some crops are already 
popular and commercialized, whereas less utilized crops still to be popularized for obvious benefits to health. Hence, the choice has already been made and the researchers need to follow.

\subsection{Consumers}

The consumer's choices largely depend on quality of the crop. Hence, the breeder has to be very cautious in identifying their choices. If the new brinjal variety has no traditional popular color or cooking quality or shape, it will be rejected outright in most of the cases. This point will be illustrated later.

\subsection{Growers}

It may happen that the new pumpkin variety has a longer growing period which does not fit in the cropping pattern. The new watermelon variety may be susceptible to serious viral diseases and so on.

\subsection{Traders}

The introduced good quality tender French beans from peri-urban areas to city of Bangalore could not retain quality of freshness in local transport, but the local variety of stringed beans did. The Alphonso Mango became over ripe (not fit for sale) in few days in Rome, while hand carried by air overnight from Mumbai.

\subsection{Researchers}

It is apparent that the shopping list of choices largely depends on government agencies, communities and individuals and breeders come last to really narrow down the choices but he/she is the master architect to decide upon the choices and define the objectives of the particular breeding project. The breeder will be the leader to prepare the blue print of the new plant structure with both hardware (morphological) and software (disease resistant and high vitamin content). It is also very important for the breeder to decide upon the breeding methodology, long or short and its economic value. During the research/construction process the breeder may make any modification necessary and will finally evaluate the new plant construct in the field with that of the blue print prepared on the paper.

The researcher has to make a follow up action to review its field performance year by year to conclude whether the new variety has (a) maintained its performance and (b) for how long a period retained its genetic characters or uniformity.

\section{Success and Failure of Choices- Truthful Experience}

\subsection{Okra (Abelmoschus Esculentus L. Moench)}

During 1962, as a young scientist I joined Indian Agricultural Research Institute (IARI), New Delhi, and was assigned to breed okra varieties. In this connection and context I met Mr. Harbhajan Singh, the father breeder of the yellow vein mosaic resistant variety (YVMV) Pusa
Sawani which became the proud of farmers nation-wide for decades. He with his wealth of knowledge on vegetables particularly okra, was kind enough to explain me in detail about his work on okra development and breeding. Further, he provided me with all germplasm including wild species of okra. By that time, the variety Pusa Sawani had become susceptible to YVMV. During 1964, I left IARI but the research was continued by my former colleagues.

By the time (1969), I joined the new Indian Institute of Horticultural Research (IIHR); Bangalore lot of research work on breeding okra resistant to YVMV had progressed at IARI and in the universities in India, but the result was far. My colleague Dr. O.P. Dutta, very energetic young scientist joined me in initiating research on breeding okra against virus diseases. After many years of research with interspecific crosses, Dr. Dutta and his team developed the variety Arka Anamika which became a commercial variety nation-wide. After several years, the disease resistance broke down and the search for development of an YVMV resistant variety continued. In India and in neighboring countries the main objective of okra breeding still remained as the YVMV resistance.

During 1977, I had an opportunity again to develop okra for the southern region of Nigeria, which was hot and humid with heavy rainfall. The indigenous okra crop was both grown and voluntary. The plants were dwarf and lower branches more or less trailing on the ground, very prickly on fruits, stem and leaves. Fruits relatively small, medium to plump, commonly six ribbed, light green mixed with pink red, prickly and fibrous. The plants looked very hardy and fresh fruits very slimy on cutting. From the breeder's point of view the plant shape could be improved to be more efficient, prickly character could be removed, fruit size and quality could be improved and yield could be enhanced tremendously. For scientists and elites, yield and quality were important.

On survey of okra almost nationwide in Nigeria, I decided to have two pronged approach to develop okra. One with relatively short term approach to introduce good varieties from tropics and second one long-term breeding to improve indigenous strains borrowing acceptable genes from abroad. After couple of years of trials with introduced varieties, the selected ones were compared with the local ones and fresh fruits put on test for judging by the common housewives for consumer's acceptance. While I was confident that Pusa Sawani, Pakistani Long or Senegal will be accepted in that order, I was shocked completely by the score of the housewives who served as judges. After repeated observation, the judges accepted the selected indigenous varieties and rejected all the introduced varieties though they were tender, long and bright colored. Though I had enough of earlier discussion with my counter-part, the Nigerian Oxford graduate Dr. Lawre Denton, who was convinced with our approach of improving okra varieties but he also could not convince the judges. In absence of any clear explanation, we all sat together for a long discussion and I analyzed the views of each judge and identified that the basis of judgment commonly depended on the methods of cooking and the taste acceptable to the common people. After few minutes of pondering, I was beamed with joy. It was the mucilaginous property which connected plate and mouth to the satisfaction of the consumer. After some years 
breeders improved indigenous lines which had tall nonprickly plant with short internodes, medium sized attractive green fruits but with high mucilaginous property. Of course, finally chosen objectives were high mucilaginous property, non-prickly nature and high yield.

\subsection{Egg Plant or Brinjal (Solanum Melongena L.)}

During my early days at the IIHR, Bangalore, a new lady grower with 10 acre land, some covered with grapes, approached me to get advice on growing vegetables. Since the young institute had not recommended yet any improved variety, I thought of suggesting IARI varieties popular in different states. In brinjal, the variety Pusa Purle Cluster which was close to local popular variety Kengeri in terms of single fruit. After months, she took me to the field and I was pleased to see an outstanding healthy crop at the bearing stage ready to be harvested next week. After a week, she returned to me with a very sad face, and I was surprised that her truck load of brinjal was not accepted in the city wholesale market and that she had no choice but to dump the fruits because she refused to pay for the transport back. She further promised not to grow vegetables again. I had no answer to her. Next morning, I sat down in the research field with my colleagues and soon we found the difference- the fruit of Pusa Purple Cluster had calyx also purple where Kengeri had green calyx, whereas Kengeri color was dark purple and Pusa Purple cluster had medium light purple color, everything else remaining the same. I was wrong in the choice of variety. I realized late that one objective of the color character can fail the crop, not in the field but in the market.

\subsection{Melons}

During late nineteen sixties at the University of Udaipur (UOU), Jobner, Rajasthan, we had done vigorous field survey and made one of the largest indigenous collections of watermelon (Citrullus lanatus (Thumb)) and muskmelon (Cucumis melo L.) germplasm in Rajasthan. With bright sunny dry water particularly at the river beds the TSS value of the muskmelon collections reached up to above 14 whereas in watermelon it was up to 13 and 14 . The diseases were minimal except some mildew. It is also indicated that melons with thick rind could withstand transport better than thin skinned ones which cracked easily during local transportation. Here the objectives of improvement were relatively high sugar, good taste and good texture and adequate transport quality.

During my post-graduate research (1959-62) at the Kansas State University (KSU), Manhattan, USA we evaluated hundreds of watermelons breeding lines which led to the selection of the breeding line, Kansas-62 as most outstanding one in yield in several of the states of USA during 1961 and 1962 which was later named as Crimson Sweet. As known by watermelon breeders this variety became popular not only in the USA but also in many other European and Asian Countries. The objectives of breeding were better fruit quality, high yield, medium size and multiple disease resistance. The dark green striped fruit of crimson sweet round in shape is thickskinned with good transport quality, with bright pink very crisp flesh giving the feeding of ice-cream, less number of very small seeds distributed uniformly in line near the skin providing large heart of flesh, easy to eat and very sweet (TSS 12-14) depending on the location.

During watermelon breeding (1969-1976) at the IIHR, the variety Crimson Sweet did not perform well in yield but was utilized in breeding Arka Manik with the same skin color as Crimson Sweet which remained most popular in many states of India for a number of decades because of its quality, high yield and disease resistance.

\subsection{Summer Squash (Cucurbita Pepo L.)}

In India, I was not familiar with squash crop but on arrival at the KSU, the first crop I saw on arrival at the farm was the left-over of squash crop at Ashland Farm during August, 1959. After a number of years, I realized that it was my monumental visit during the beginning of my research career and I will be happy to tell you why?

During my first encounter with Prof. Charles V. Hall, he signed for me the credits/courses to be undertaken and to get registered. Next day he drove me to the Ashland Horticulture Farm and we landed at experimental plots of cucurbits. Before reaching the plot I experienced some strange unknown smell in the air. The squash crop was already harvested, and most of the plants were either dead or going to die soon with some damaged fruits. Soon I realized that I was trampling not only damaged plants but also bold fowl smelling insects crawling all over the plants and plots. The Professor explained that it was the serious insect pest, squash bug damaging the crops severely and he further took me round to various plots of watermelon, muskmelon, pumpkin and so on. I forgot about the visit later but left me to think about the crop and the pest knowingly or unknowingly. Whenever I had chance to visit library, unintentionally I used to go through literatures on squash. On my own, while collecting literature on squashes, sometimes I used to clarify with Prof. Hall. On completion of one or two semesters, it was time to decide on my thesis research work and I myself said, I wished to work on squash and by that time I could know that the serious problem threatening the squash crop was insect pests only. I knew by myself that the objective of breeding was resistance to squash bug damaging fruits and spotted and striped beetles feeding on young seedlings. My professor said, go ahead. After 4 years I ended up in completing the work on studying inheritance of insect resistance (spotted and striped beetles) in squash plants. I was very pleased that I had taught myself how to identify the objectives of breeding squash. On my return to India, I encouraged my post-graduate students to identify and propose their objectives of research work.

During research work at IIHR, I introduced some varieties of squash and identified the American variety Patty Pan, an attractive white and outyielding in the experimental plots. Further, large scale trial was held at the Shimsha River bed near Maddur, Karnataka, India, in collaboration with the Department of Horticulture. The results were outstanding with regard to plant growth, health and yield. The piles of fruits were on sale on the road side of highway near the field plot and of the gate of the Horticultural Experiment Station, Maddur. The visitors and farmers were curious to know about this new wonder crop which did not look like any other crop. We the researchers were pleased with success and thought it to 
become the new crop of the future. But today even after about forty years, the Patty Pan is hardly known in Karnataka but continues to be the crop of USA. The reason is neither growers nor consumers knew the utility of this crop; they do not know how to grow and how to consume though some of them cooked in sambhar like that of pumpkin or ashgourd. Here the objectives of improvement in quality, yield and adaptability in the field were not wrong. The extension team failed to popularize this short duration bushy (space-saving unlike any other vine cucurbits) and high yielding crop, among the farmers; and good cooking and nutritive qualities same as common gourds, among the consumers. However, now some long type squashes have started coming in at food stores only and hopefully Patty Pan will get its due not very soon, if popularised.

\subsection{Roundmelon or Tinda (Citrullus Vulgaris Var Fistulosus Watt)}

The roundmelon or tinda common to northern states of India was introduced at the IIHR, for southern states, similar to the introduction of squash from the USA. On conclusion of the breeding work, the high yielding variety Arka Tinda was released nationwide during 1970's. The National Seeds Corporation Ltd. multiplied the seeds on large scale. The northern states utilized it very well, whereas in the southern states it did not take off. Arka Tinda had the same fate as of Patty Pan, because of the lack of support from the extension wing. After about 40 years, I am surprised to see locally grown roundmelon along with other vegetables on some of the streets and at food stores of Bangalore. I guess the increase in local demand of this crop is caused more by the increase in cosmopolitan population of the city.

\subsection{Pumpkin (Cucurbita Maxima (Duch))}

During researches at the IIHR (1970's) the pumpkin variety Arka Suryamukhi was bred and released. The objectives of breeding was to develop small family size, attractive in color, good flesh, high in food value, long shelf life, high yield, medium plant growth and resistance to red pumpkin beetle. The fruit of Arka Suryamukhi is distinct by color in vegetable markets. It is very surprising that fruits of Arka suryamukhi are still available in all parts of Karnataka, and can be seen in the vegetable markets of Kerala, Tamil Nadu, Andhra Pradesh and Maharashtra.

Isn't it surprising that (a) this cross-pollinated variety has retained its characters, and (b) sustained the demand of the consumers through 4 decades? I think the objectives of improvement were right and the success was more than expected. The growing trend of small family and demand of small fruit and suitable cooking ability (with no cut fruit requiring refrigerator), long shelf-life matched very well with the original objectives of breeding. My former colleague Dr. O.P. Dutta, made further genetic studies on the variety Arka Suryamukhi. I hope breeders are lucky as this in breeding other crops.

\subsection{Spinach or Palak (Beta Vulgaris var. Bengalensis Rox)}

Some of the semi-arid and arid regions of Rajasthan had near salinity or high salinity of soil and water leaving little choice of crops for the farmers to grow. At the UOU, Jobner campus, we faced this problem and tried to mitigate it by introducing improved technology by selecting salt tolerant crops, by improving crop management practices and by developing salt tolerant varieties. Some of the crops susceptible to relatively high $\mathrm{pH}$ were grown successfully with improved management technology. The melons performed well. Palak grew well and was much liked by the local consumers. Hence, the objective was to breed high yielding salt tolerant palak variety with high in Vitamins A and C content. In due course, the variety Jobner Green was developed which became popular with farmers both in saline and non-saline soils. The increased yield was obtained by its large-size leaves, vigorous tall growth with prolific branches allowing 2-4 harvests depending on the size of plant growth. Some years ago, I saw Jobner Green in the experimental plot of one of the research institutes, where it was being utilized as a donor parent in the breeding programme.

For the last couple of years, I have been observing some changes in palak either on street carts or in food stores in Bangalore. During 1970's hardly palak was seen in Bangalore because neither it was grown nor consumed but people like us who used to consume it, looked for it. In the beginning of the millennium (2000), the palak was available both on the streets as well as in the food stores in the form of cut large leaves. But for the last couple of years, the fresh very tender palak seedlings with small leaves and small roots have started coming in on a high price. It cooks easily and is much tastier. Would the researchers change their objective of breeding?

\section{Prospects}

It is clear that consideration of choices and its selection are prelude to define the objectives of any vegetable breeding project. And no project of breeding improved varieties will succeed in commercial production unless objectives are properly and correctly designed based on choices selected.

Further, it is preferable and economical to use such breeding techniques which will allow saving of time and money. In the developing world, the introduction and selection of vegetable crops have brought about tremendous success in enhancing crop production. Hence, the introduction of new germplasm will lead to saving in cost and time and in making improved variety available to farmers relatively earlier.

Of course, cross breeding must be undertaken for longterm as per necessity and where probably introduction effort has not succeeded. Here also I have seen breeders struggling to in-corporate disease resistance for years in some countries but not succeeded. In one Asian country my visit to the Experiment Station revealed that they could not succeed in developing bacterial wilt tomato variety even after 8 years and they did not know that the resistant variety was already available in another Asian Country.

In another country, the extension agent was worried about the complaint of farmers that the Capsicum variety 
had run down and sweet fruit had become pungent and unacceptable to consumers. On visit to the large field of Capsicum, I discovered hat Capsicum was grown along with highly pungent chillies and the farm was repeating it for the last 4-5 years and collecting the seeds of capsicum every year; of course, chilli was traditional crop of the area and Capsicum was introduced not long ago. The farmer was advised to grow them separately in isolation to produce good seeds. This indicated clearly that it is not only important to use improved varieties but it is also necessary that progressive growers are allowed first to learn about its cultivation for others to follow.

Acknowledgements are due to institutions where the author served and gained some of these experiences.

\section{Acknowledgements}

The author acknowledges the workdone at the various institutes and the contribution of co-research workers mentioned in the paper.

\section{Reference}

[1] Nath, Prem (2013). Personal experience and visits. 